\title{
Integrating life cycle costs and environmental impacts of composite rail car-bodies for a Korean train
}

\author{
Pascale Schwab Castella • Isabelle Blanc • Marcel Gomez Ferrer • Bastien Ecabert • \\ Martyn Wakeman • Jan-Anders Manson • Daniel Emery • Seong-Ho Han • \\ Jinglan Hong • Olivier Jolliet
}

Received: 1 April 2008 / Accepted: 10 May 2009/Published online: 17 June 2009

(C) Springer-Verlag 2009

\begin{abstract}
Background, aim, and scope A coupled Life Cycle Costing and life cycle assessment has been performed for car-bodies of the Korean Tilting Train eXpress (TTX) project using European and Korean databases, with the objective of assessing environmental and cost performance to aid materials and process selection. More specifically, the potential of polymer composite car-body structures for the Korean Tilting Train eXpress (TTX) has been investigated. Materials and methods This assessment includes the cost of both carriage manufacturing and use phases, coupled with the life cycle environmental impacts of all stages from raw material production, through carriage manufacture and use, to end-of-life scenarios. Metallic carriages were compared with two composite options: hybrid steel-
\end{abstract}

Responsible editor: Tak Hur

P. Schwab Castella $(\bowtie) \cdot$ I. Blanc $\cdot$ M. Gomez Ferrer $\cdot$ O. Jolliet Institute of Environmental Science and Technology,

Ecole Polytechnique Fédérale de Lausanne (EPFL),

1015 Lausanne, Switzerland

e-mail: pascale.schwab@unil.ch

P. Schwab Castella $\cdot$ I. Blanc

Institute of Land Use Policies and Human Environment,

Faculty of Environment and Earth Science,

University of Lausanne, Industrial Ecology Group,

1015 Lausanne, Switzerland

\section{Blanc}

Centre Energétique et Procédés, MINES ParisTech, BP 207, rue Claude Daunesse,

06904, Sophia Antipolis Cedex, France

M. Gomez Ferrer

JG Proyectos División Medio Ambiente, Torrent de Vallmora 24-26 $1^{\mathrm{o}} 2^{\mathrm{a}}$, El Masnou,

Barcelona, Spain composite and full-composite carriages. The total planned production for this regional Korean train was 440 cars, with an annual production volume of 80 cars.

Results and discussion The coupled analyses were used to generate plots of cost versus energy consumption and environmental impacts. The results show that the raw material and manufacturing phase costs are approximately half of the total life cycle costs, whilst their environmental impact is relatively insignificant (3-8\%). The use phase of the car-body has the largest environmental impact for all scenarios, with near negligible contributions from the other phases. Since steel rail carriages weigh more (27-51\%), the use phase cost is correspondingly higher, resulting in both the greatest environmental impact and the highest life cycle cost. Compared to the steel scenario, the hybrid composite

B. Ecabert $\cdot$ M. Wakeman $\cdot$ J.-A. Manson Laboratory of Polymer and Composite Technology, EPFL, 1015 Lausanne, Switzerland

\section{Emery}

Laboratory for Intermodality and Transport Planning, EPFL, 1015 Lausanne, Switzerland

\section{S.-H. Han}

Advanced Material Tilting Train System Research Center,

Korea Railroad Research Institute,

\#360-1, Woram-Dong,

Uiwang-City, Gyeonggi-Do 437-757, Korea

J. Hong · O. Jolliet

School of Public Health, University of Michigan,

Ann Arbor, MI 48105, USA 
variant has a lower life cycle cost (16\%) and a lower environmental impact (26\%). Though the full composite rail carriage may have the highest manufacturing cost, it results in the lowest total life cycle costs and lowest environmental impacts.

Conclusions and recommendations This coupled cost and life cycle assessment showed that the full composite variant was the optimum solution. This case study showed that coupling of technical cost models with life cycle assessment offers an efficient route to accurately evaluate economic and environmental performance in a consistent way.

Keywords Composite material · Cost modelling · LCA · Life Cycle Assessment · LCC · Life Cycle Costing · Railway • Train · Transport

\section{Background, aim, and scope}

After a period of declining utilization, the use of rail passenger transport is now increasing and is predicted to continue this increase. This is due to the speed and convenience of rail in comparison to the increasing traffic densities and delays of personal transport. Railtrack in the UK predicts demand will increase 30\% between 2000 and 2010, and Dutch Railways foresees a $50 \%$ increase by the year 2010 (Bartlett 2000). This will drive a demand for increasing train car production. Train companies are not like airlines that buy models identical to their competitors and gain the cost advantages of mass production. Instead, train companies tend to order custom designs in small batches to suit local conditions. Thus, the rail carriage producers must manufacture large components (hundreds of cubic meters in volume) at low production volumes (Wilson M for 'Bombardier Transportation' 2002).

It is becoming increasingly important to consider both the costs and the environmental impact of new technologies at the early stage of product development and design, when the realm for action is greatest. While rail travel is commonly considered a 'clean' method of transportation compared to automobiles or aircraft, there are still many possible and necessary improvements to be investigated.

A solution to reduce rail carriage mass and hence the use phase environmental impact is weight reduction of decorative, semi-structural, and structural rail body components. This weight reduction can be achieved by replacing the steel with polymer composite materials or aluminium, both of which have been used to varying degrees (Guillemot and Grunevald 2000; Carruthers 2004). Glass fibre composite materials are being used for decorative and semi-structural applications (Batchelor 1981; Robinson 2000). However, only limited use of carbon fibre reinforced polymers (CFRP) has been seen for structural rail applications.
From a methodological point of view, an increasing number of studies (Hunkeler et al. 2008) show the interest of evaluating both Life Cycle Cost and Environmental Life Cycle performance in a consistent way, but few studies detail the manufacturing stage, which is often crucial for decision-making.

This article presents the results of a study of potential CFRP rail car-body structures for the Korean Tilting Train eXpress (TTX). The objectives were to assess the life cycle cost and life cycle impact of alternative train car-bodies, with a detailed assessment of the manufacturing stage. The study consists of a life cycle assessment (LCA) of such structures, which has been coupled with a detailed cost analysis. Specifically, the project steps were the following:

1) Apply a technical cost modelling method to the specific case of train car-body manufacturing and assess its life cycle costs.

2) Develop an environmental LCA that is fully consistent with the Technical Cost Modelling (TCM: Wakeman and Månson 2005) approach, extending it to a more comprehensive Life Cycle Costing approach that covers all life cycle stages.

3) Apply the two methods to the case study of the Korean Tilting Train, comparing different solutions (composite, aluminium, or steel). The whole assessment has been restricted to car-body alternatives and did not cover the whole train.

4) Analyse and interpret results in combination in order to identify and optimise key parameters influencing costs and environmental impacts over the whole life cycle.

\section{Life Cycle Assessment (LCA)}

Life Cycle Assessment (LCA) is a decision support tool to quantify the effects of goods or services on resource usage and emission burdens. LCA helps prioritize actions to prevent pollution and reduce the consumption of resources, ultimately leading to products with the potential for improved life-cycle performance. An LCA accounts for resource consumption and emissions at every stage in a product's life cycle, termed "from cradle to grave", spanning raw material extraction, energy acquisition, manufacturing, use, re-use, recycling, recovery and waste disposal. This is used to calculate associated impacts. Practitioners consider various indicators, including climate change, stratospheric ozone depletion, tropospheric ozone (smog) creation, eutrophication, acidification, toxicological effects, resource depletion, water consumption, and land use. For more details, see Jolliet et al. (2005) or the ISO 14040 standards (ISO 14040 2006; ISO 14044 2006). 
Several life cycle assessments on trains have been conducted, including the following: The Swissmetro project (Mingot and Baumgartner 1997; Baumgartner et al. 2000), the ecoinvent database (Spielmann et al. 2003), a life cycle inventory of transportation systems (Maibach et al. 1999), the EVENT-German Intercity train (Nolte 2003; von Rozycki et al. 2003), and a LCA of Shinkansen vehicles (Nagatomo et al. 1997; Kirimura et al. 1997). These studies all conclude that the operational phase dominates life cycle impacts. They find that the main methods for reducing energy consumption during the operation phase are through mass reduction, maximisation of occupancy and utilisation, a more aerodynamic train design, and energy recovery while braking. The choice of energy type can also significantly affect the environmental impact.

Many other LCA studies have been performed to assess life cycle impacts of composite materials for transportation purposes. For example, the LCA of an underbody panel for a car had been reported by Margand et al. (2003), and Gibson (2000) presented the LCA of advanced materials for automotive applications. Similar to trains, they find that the use phase is an important factor in the environmental load. This is largely due to the energy consumption during this phase, which is directly linked to the weight of the vehicle. Therefore, we propose reducing the impact of the use phase via weight reduction. This requires detailed knowledge of the processes, materials, and energy consumption involved, as well as the associated emissions. Such data needs to be collected in cooperation with the producers and directly at the production plant. Additionally, it is important to use an LCI database adapted to the local parameters (the energy production and resulting impact, for example, may be very different between two countries).

\subsection{Technical cost modelling}

Cost modelling approaches for composite manufacturing have been reviewed and presented by (Wakeman and Månson 2005). Beyond 'rule of thumb' approaches that use experience-based estimations, these can be summarised as comparative techniques, process-oriented cost models, parametric cost models, relational databases, objectoriented system modelling tools, and process flow simulations. Parametric models offer flexibility and easy manipulation of process and economic factors for sensitivity studies. One such model is Activity Based Costing (ABC) accountancy. ABC attributes overhead costs to goods and services based on the underlying activities that generate the costs. However, since ABC is based upon historical data, it is of limited use when new processes are considered (such as CFRP for rail carriages). In cases where detailed information is not available to define overhead costs, not all variable costs will be activity-based, and therefore volume-based approximations are applied (for example, a ratio of direct to indirect labour).

The method used in this study is Technical cost modelling (TCM) methodologies. TCM is related to activity based costing but uses engineering, technical and economic characteristics associated with each manufacturing activity to evaluate its cost (Wakeman and Månson 2005). The total manufacturing cost is divided into contributing cost elements, thereby reducing the complex problem of cost analysis into a series of simpler estimation problems. The contribution of these elements to the part's manufacturing cost is derived from inputs of process parameters and production factors (e.g. production rate, labour and capital requirements, and production volume). These elements are calculated based on engineering principles, economic relationships, and manufacturing variables. Both dedicated manufacturing scenarios (fixed costs amortized over the number of parts produced) and utilization-based plants (plant capacity amortized across multiple parts or clients) were considered. Input data for this case study were based upon interviews and commercial estimates for materials and process equipment. In order to cover the full life cycle costs, these detailed material and manufacturing costs are complemented by electricity use costs and end of life costs or benefits when recycling.

\subsection{Coupled LCA and LCC}

Environmentally optimized designs and new lightweight technologies will only be widely implemented if the economic interest can be demonstrated and if optimization is carried out both on environmental and cost aspects in parallel. Life cycle costing (LCC) is a methodology that combines with LCA to assess the total cost of a system or product over its entire life span. It is defined to include the costs of planning, research and development, production, operation, maintenance and disposal (IEC60300 1996).

Current LCC and LCA concepts and procedures are generally incompatible, as they are designed to provide answers to very different questions. LCA evaluates the environmental performance of alternative product systems, in a holistic way, aiming to consider all important causally-connected processes. LCC compares the costeffectiveness of alternative investments or business decisions from the perspective of an economic decision-maker, such as a manufacturing firm or a consumer. In order to combine both elements into a coherent analysis, Norris (2001) proposed two methods for connecting LCA with LCC, in which LCC shares the same starting point as LCA and is then expanded to cover external costs. Rebitzer et al. (2003) proposed an LCA-based LCC method, which 
utilizes an LCA model as a basis for cost estimations to compare life cycle costs of alternatives and detect direct and indirect (hidden) cost drivers. Other authors have proposed the following alternative indexes: Value Ratio Model (Vogtländer et al. 2001), Econo-Environmental Return (EER) (Bage and Samson 2003) and Social Life Cycle Costs (SLCC) (Dahlbo et al. 2007).

An LCA-based LCC case study of the floor in a doubledeck railway carriage (Hunkeler et al. 2008) found that the purchase cost of materials was $3 \%$ of the overall life cycle costs, while cleaning and maintenance accounted for $75 \%$ over the life cycle, and use costs (allocated energy consumption due to the weight of the floor) contributed $16 \%$. However, no treatment has been identified to address the life cycle costs and impacts of train car-bodies in carbon fibre reinforced polymers. In the following section, we present the method developed for coupling the life cycle impacts with a detailed assessment of manufacturing process costs using technical cost modelling.

\section{Method and goal definition}

3.1 Principle of the combined technical cost modelling and life cycle assessment

The approach developed in this case study extends the Technical Cost Modelling to other life cycle stages and combines it with Life Cycle Assessment methods and tools based upon a common detailed analysis of the processes involved in all life cycle stages. The Technical Cost Modelling gives information at a higher level of detail at the manufacturing stage, thus providing a more refined decision-making basis for this stage (Fig. 1).

For each process, the cost model (Wakeman and Månson 2005) lists material and energy consumptions, required labour, and other auxiliary inputs, depending on train body characteristics. Cost information was supplied by the project industrial partners and by direction contact with multiple material and equipment suppliers to deliver the detailed global cost. The model predicts the manufacturing cost and cost segmentation as a function of production volume. Cost versus production volume relations are given together with segmentation of the total production cost into material, direct labour, overheads (indirect labour and plant costs), maintenance, energy, consumables, tooling, transportation and sub-contracted costs.

In parallel, the ecoinvent life cycle inventory database is used to evaluate the life cycle impacts based on the TCM inventory. The IMPACT 2002+ method (Jolliet et al. 2003) has been used to assess the environmental impacts of the whole life cycle (including all stages from raw material extraction, manufacturing, production of the rail carriage, the use period and possible disassembly and disposal, recycling or recovery), and results have been compared and confirmed using the CML method (Guinèe et al. 2001).

Results will first be presented separately for impacts and cost. An integrated discussion follows based on a combined representation of primary energy consumption versus costs.

\subsection{Functional unit}

The functional unit identified for this study is one car-body for the TTX train, with a lifetime of 25 years and used over $7,500,000 \mathrm{~km}$. The TTX train is an electric train, formed of six cars: two motorized control cars with pantograph, two motorized cars, one trailer car and one handicapped car (Fig. 2). The car-body is the skeleton of the train cars. It is formed by the under-frame, the panel structure (side, roof and end structure) and an innerframe to maximise strength properties. One TTX car-body is $2.86 \mathrm{~m}$ wide, $2.57 \mathrm{~m}$ high and $23.5 \mathrm{~m}$ long. Each of the six car-bodies of the train has the same weight.

\subsection{System boundaries}

The system boundary includes all the processes necessary to perform the system function, which here includes the processes for raw material extraction, manufacturing, and use of the car-body. It excludes infrastructure and maintenance, because they are assumed to be the same for all scenarios over the 25-year life span (Fig. 3). The subsystem "electricity production" is an important part of the whole system and requires a specific evaluation accounting for the specific Korean electricity mix. Use-phase labour costs (train driving and maintenance of car-bodies) are considered to be the same for each scenario, and thus have not been taken into account.

\subsection{Scenario description and modelling}

This study compares four car-body scenarios:

- Scenario 1: Full composite car-body, with a carbon fibre epoxy aluminium honeycomb sandwich structure and a stainless steel under-frame. This represents an ideal and extreme scenario (in terms of low mass) for the future, where an all-metallic frame would be unnecessary.

- Scenario 2: Hybrid composite car-body, with a carbon fibre epoxy aluminium honeycomb sandwich structure, a mild steel inner-frame and a stainless steel under-frame. This is the scenario being explored as an existing alternative to traditional metallic car-bodies. 


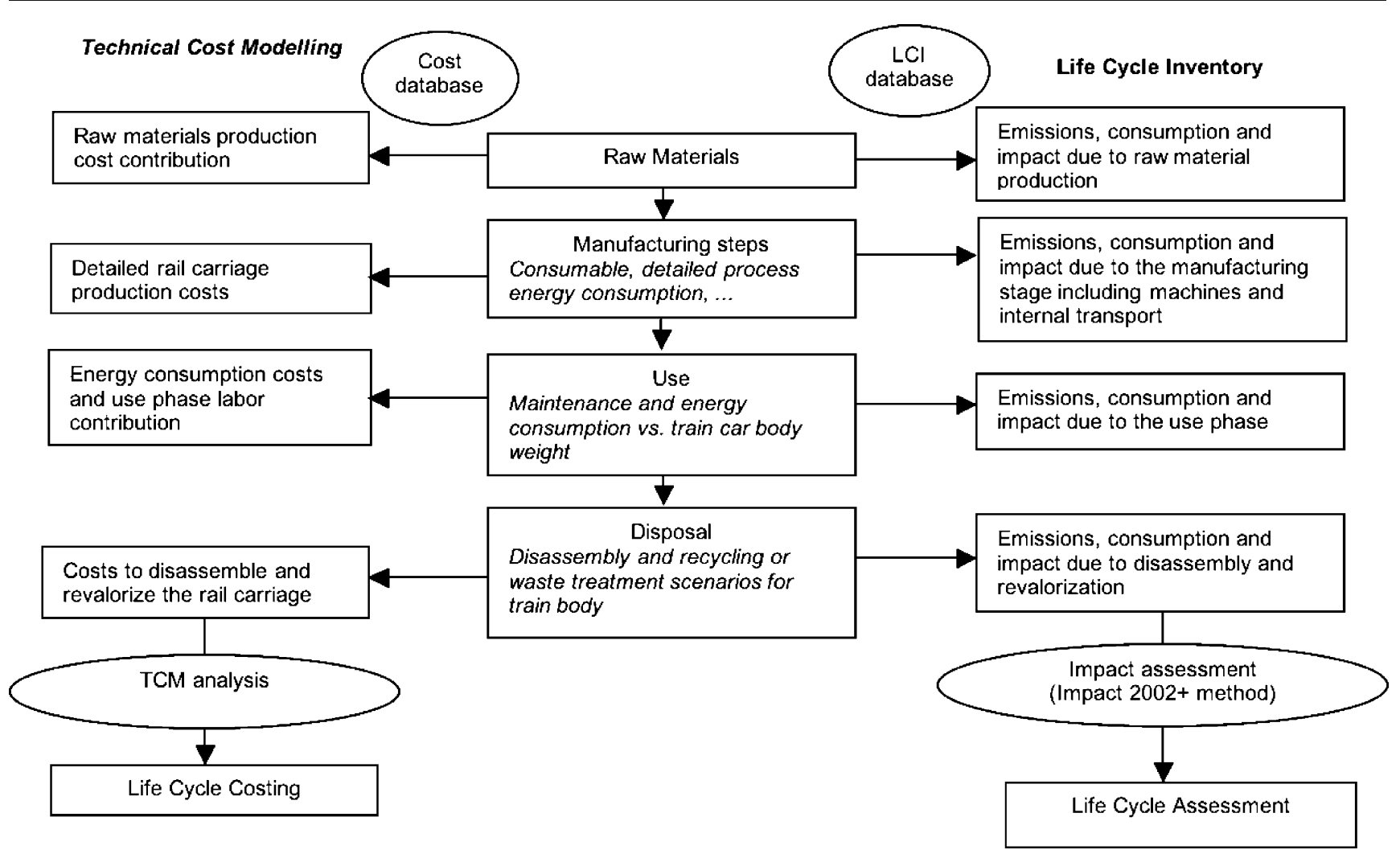

Fig. 1 Combined technical cost modelling (TCM) and life cycle assessment (LCA)

- Scenario 3: Aluminium car-body, with a 100\% aluminium structure. This scenario is a potential alternative to composite scenarios.

- Scenario 4: Stainless steel car-body, with a $100 \%$ stainless steel structure. This is the current option.

The detailed description of each scenario is shown in Table 1.

For each of the scenarios, the manufacturing process was disaggregated into unitary activities enabling individual steps to be characterized in terms of cost and energy or material requirements. Figure 4 presents a schematic view of the manufacturing plant for the hybrid car-body scenario. It involves the following successive steps:

1. The first pre-impregnated composite layer (also called "prepreg", see Campbell 2004) skin is laid up in the mould.

2. The mould is transferred to the autoclave for the curing of the first skin.

3. Once the first skin is cured, the mould is taken out of the autoclave for lay-up of the aluminium honeycomb core with Bondex adhesive film, the steel inner-frame and the second prepreg skin.

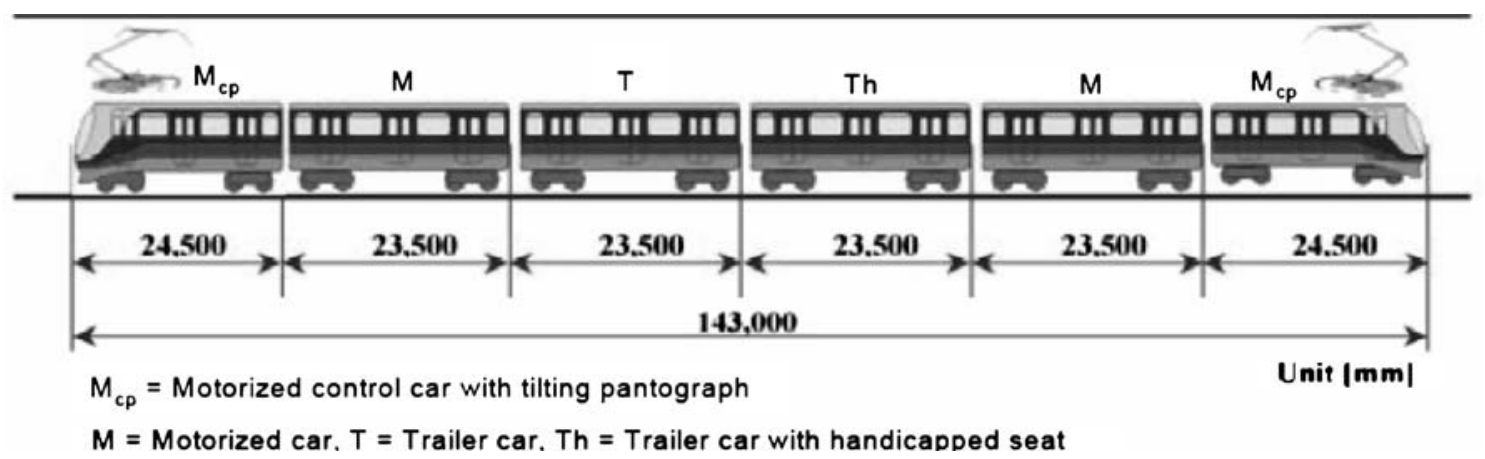

Fig. 2 Tilting train with six cars 
Limits of railway system

\section{Limits of our study: One car body}

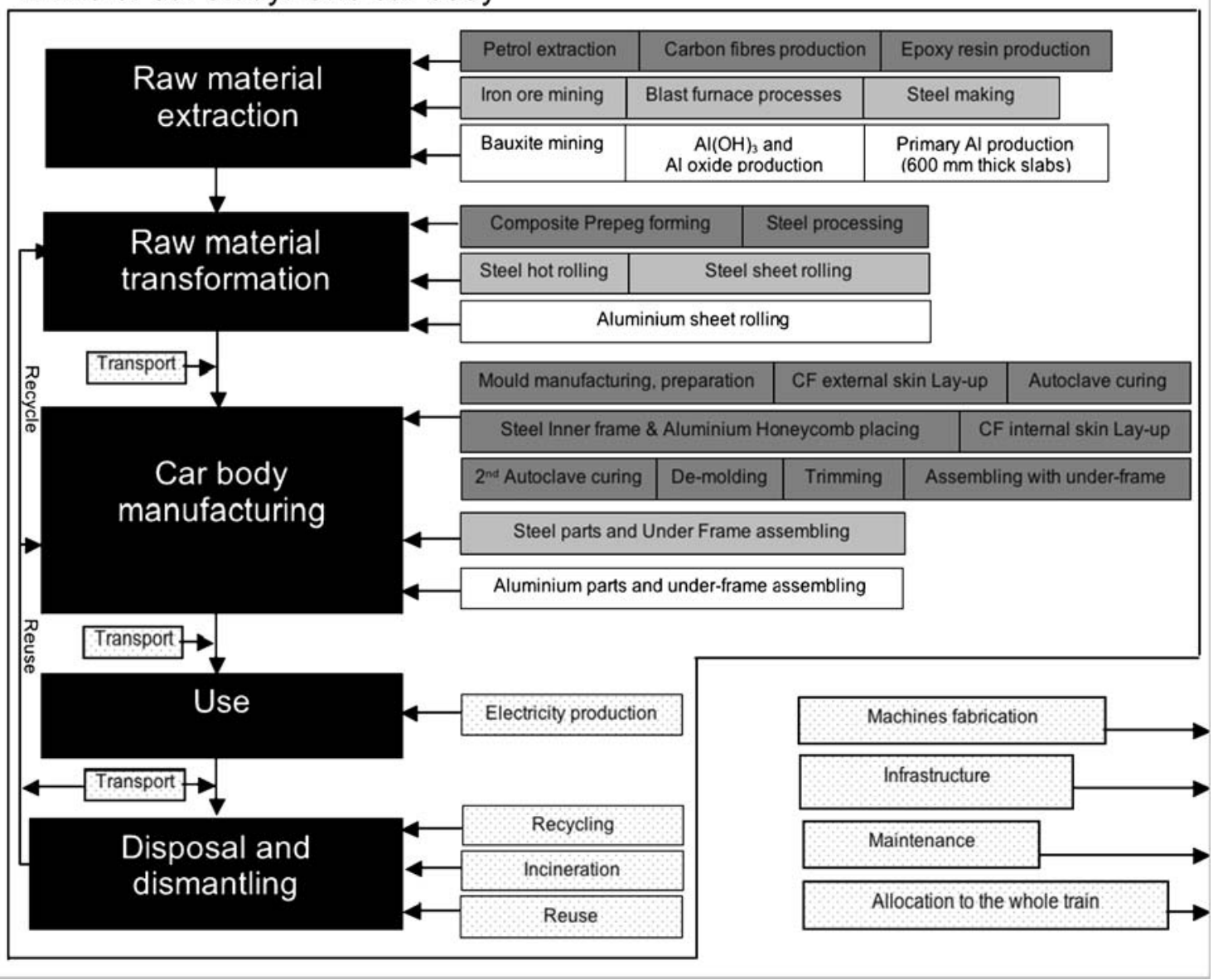

Fig. 3 System boundaries

4. The mould is transferred to the autoclave for the curing of the second skin.

5. The mould is taken out of the autoclave, and the part is then demoulded and trimmed.
6. The finished composite part goes to the assembly cell, where it is assembled with the steel under-frame by means of rivets. The carriage structure is complete.

Table 1 Composition of each scenario

\begin{tabular}{|c|c|c|c|c|}
\hline & $\begin{array}{l}\text { Scenario 1: Full composite } \\
\text { car-body } 7.6 \text { tonnes }\end{array}$ & $\begin{array}{l}\text { Scenario 2: Hybrid car-body } \\
\text { (composite \& steel) } 8.5 \text { tonnes }\end{array}$ & $\begin{array}{l}\text { Scenario 3: Aluminium } \\
\text { car-body9 tonnes }\end{array}$ & $\begin{array}{l}\text { Scenario } 4: \text { Steel } \\
\text { car-body } 11.5 \text { tonnes }\end{array}$ \\
\hline Under Frame & Stainless Steel: 5.3 tonnes & Stainless Steel: 5.3 tonnes & No under frame & $\begin{array}{l}\text { Stainless Steel: } \\
4.2 \text { tonnes }\end{array}$ \\
\hline $\begin{array}{l}\text { Side, roof, end } \\
\text { structure }\end{array}$ & $\begin{array}{l}\text { Composite : } 2.08 \mathrm{t} \\
-0.38 \mathrm{t} \text { Aluminium } \\
\text { Honeycomb } \\
-1.7 \mathrm{t} \text { CFRP } \\
-1.0 \mathrm{t} \mathrm{CF}, \\
-0.7 \mathrm{t} \text { Epoxy resin } \\
\text { Bondex : } 0.22 \mathrm{t}\end{array}$ & $\begin{array}{l}\text { Composite : } 1.78 \mathrm{t} \\
-0.38 \mathrm{t} \text { Aluminium } \\
\text { Honeycomb } \\
-1.4 \mathrm{t} \text { CFRP } \\
\cdot 0.84 \mathrm{t} \mathrm{CF}, \\
\bullet 0.56 \mathrm{t} \text { Epoxy resin } \\
\text { Bondex : } 0.22 \mathrm{t}\end{array}$ & Aluminium: 9 tonnes & $\begin{array}{l}\text { Stainless Steel: } \\
7.3 \text { tonnes }\end{array}$ \\
\hline Inner Frame & No inner frame & Mild Steel : 1.5 tonnes & No inner frame & No inner frame \\
\hline
\end{tabular}

$\mathrm{CFRP}=$ Carbon fibres reinforced polymer, $\mathrm{CF}=$ Carbon fibres 


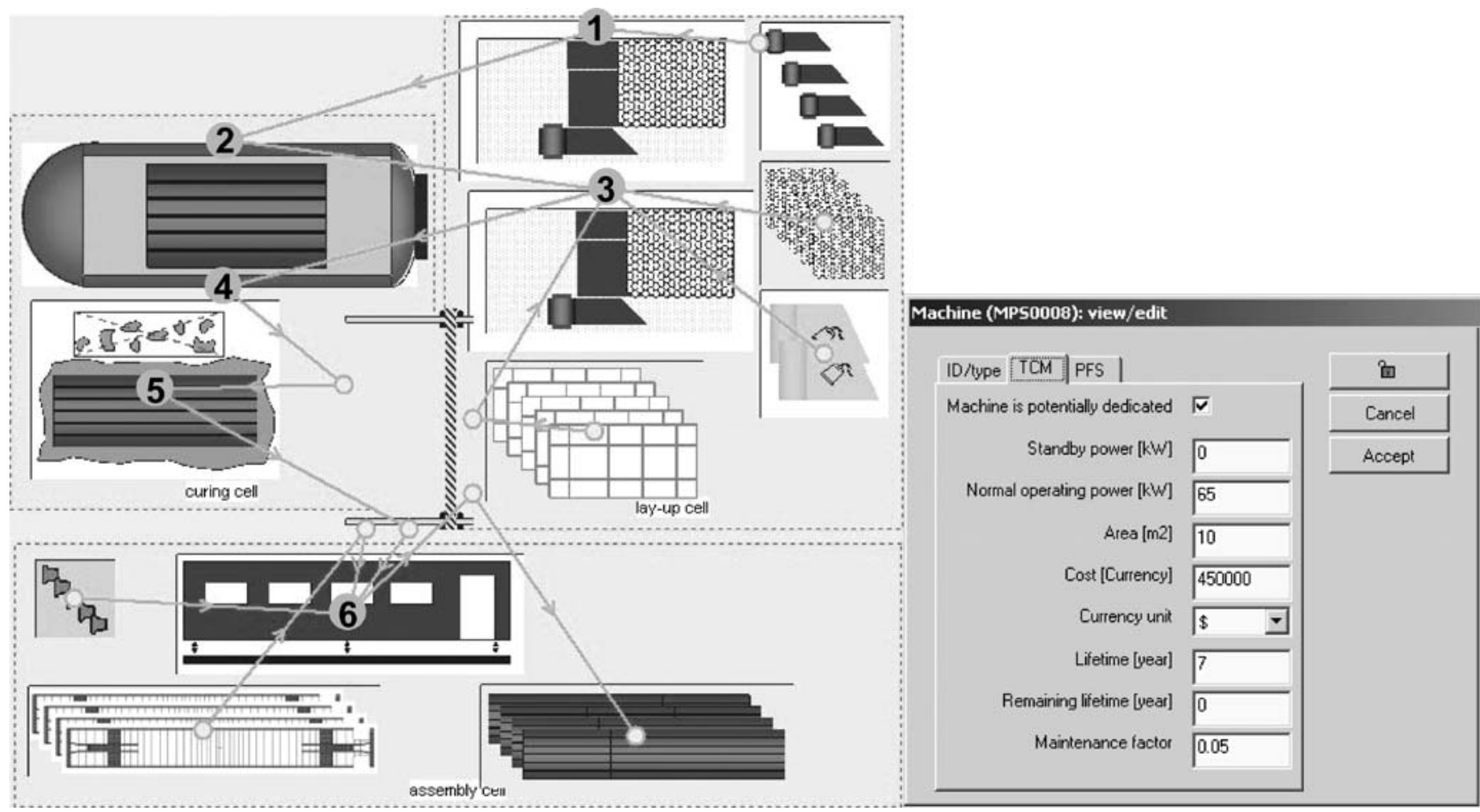

Fig. 4 Manufacturing plant of the hybrid car-body scenario process, schematic plan and cost view

For each process step, operating power, plant area, equipment cost, lifetime, remaining lifetime and maintenance factors are recorded. Korean manufacturing costs were only available for the composite scenarios, therefore the main scenario comparisons presented in this article are based on European cost data. Korean costs for the hybrid composite scenario will be addressed and presented in "Section 5.4", with the main differences in cost due to lower direct labour costs and electricity prices in Korea.

\subsection{End of life}

Currently, Korean metallic carriages are reused as restaurants, therefore we have considered this as a reference scenario for the environmental assessment of the end of life. The composite material can be guaranteed for train usage for up to 25 years, after which it can be used as a restaurant for the next 25 years. All environmental and economical impacts of end of life treatments (adaptation to the new application and elimination or treatment after this use) are allocated to the new product. This new product benefits from the fabrication of the first product, while endorsing the responsibility for adaptation to the new application and final end of life treatment and related potential impacts. Furthermore, research in composite material recycling during the next 25 coming years could bring new opportunities for these complex materials.

In this reference scenario, we assume a standard wrought alloy with $10 \%$ recycled aluminium (Althaus et al. 2003). A sensitivity study has been carried out for the aluminium scenario, considering a typical recycling rate for the transport sector of $90 \%$ (85-95\%) according to The Global Aluminium Recycling Committee (2006) and EAA (2009). We assume that there is a closed loop recycling. This also corresponds to the substitution of new primary aluminium in a separate application. The results are presented in part 5.4 for both costs and environmental impacts.

\subsection{Inventory data: sources and quality}

The life cycle assessment was performed in accordance with ISO 14040 standards. Korean data have been used as much as possible. Where Korean data were not available, we have used the ecoinvent Database, a state-of-the-art European database developed by the Swiss Centre for Life Cycle Inventories, which contains more than 2,500 processes (Frischknecht et al. 2005; Spielmann et al. 2003; Spielmann and Scholz 2005). For the production of carbon fibres, we have used the IDEMAT Database (developed at the Delft University of technology, the Netherlands). The inputs for the material composition of the car-bodies and energy production of Korean mix were defined following Hankuk Fibers and KRRI information.

For prices and costs, European data were used for the main scenario comparison, since Korean labour cost data were only available for the two composite scenarios. To better understand the differences in cost, particularly the influence of labour and electricity, we have compared the 
Korean and European life cycle costs for the hybrid composite scenario and present the results in "Section 5.4"

Data qualification assessment is important when publishing LCA inventory results. A table was used to reference and to qualify all the data used, in order to provide a good overview of their strengths and weaknesses and to enable their use in the evaluation phase. This table attempts to assess the level of accuracy of each dataset at three different levels:

- Relevance of the database data used versus the data ideally required This represents the relevance of the database data (corresponding to a specific type of technology, geographical location, and time period) to the reality of our scenarios. Even with 2,500 processes, such databases are limited and, hence, the labels "good", "medium" or "low" have been used to describe this relevance.

- Quality of the database inventory This information is given in the database itself. It gives information on the source of the inventory (calculations, measurements, hypothesis, etc.) and of the representativeness of each data.

- Quantity accuracy The different scenarios modelled in this study are based on existing car-bodies. However, the quantity of materials used for the manufacturing phase and the related losses were not fully available. Therefore, the data accuracy has been attributed as "good", "medium" or "low" according to expert judgement and quality of the underlying data. Uncer- tainties on the amounts of raw material do affect the reliability of the results and have to be identified. For example, no information was available concerning the material composition and weight of the autoclave oven, so this has been evaluated based on expert judgment.

An example of data qualification is given in Table 2 for the scenario 2 (Hybrid composite) raw material extraction phase.

\subsection{Korean electricity production mix}

No specific Korean electricity production mix data exist in reference databases such as ecoinvent. Thus, we used electricity production mix data from the Korean database, KELA (2005), (37\% hard coal, 15\% gas, $8 \%$ oil, $38.9 \%$ nuclear, $1.3 \%$ hydropower), assuming European electricity production technologies. For comparison, the European electricity production mix is $25 \%$ Lignite and Hard Coal, 15\% Gas, 7\% Oil, 36\% Nuclear, 16\% Hydropower, and 1\% Windpower (Dones et al. 2004).

\section{Life cycle inventory}

\subsection{Energy consumption in the use phase}

Since the use phase is a dominant source of impact, it has been studied in more detail in this life cycle assessment. Two important parameters were identified: the quantity of

Table 2 Data quality for scenario 2, Hybrid composite, Raw material extraction

\begin{tabular}{|c|c|c|c|c|c|}
\hline Material, Process & Data origin & Data name, ID & $\begin{array}{l}\text { Database data } \\
\text { relevance }\end{array}$ & $\begin{array}{l}\text { Database } \\
\text { inventory } \\
\text { quality }\end{array}$ & $\begin{array}{l}\text { Quantity } \\
\text { accuracy }\end{array}$ \\
\hline $\begin{array}{l}\text { Iron ore extraction } \\
\text { and steel production(rivets, } \\
\text { innerframe and } \\
\text { underframe) }\end{array}$ & Ecoinvent 1.0 & $\begin{array}{l}\text { Steel, converter, chromium } \\
\text { steel } 18 / 8 \text {, at plant/RER } \\
\text { (primary steel) } \\
\text { Steel, electric, chromium } \\
\text { steel } 18 / 8 \text {, at plant/RER } \\
\text { (secondary steel) } \\
\text { Steel, converter, low alloyed, } \\
\text { at plant/RER } \\
\text { Steel, electric, un- and } \\
\text { low-alloyed, at plant/RER }\end{array}$ & $\begin{array}{l}\text { Medium } \\
\quad \text { (Eu technology) }\end{array}$ & Good & Medium-low \\
\hline $\begin{array}{l}\text { Epoxy extraction and } \\
\text { thermoset mix production }\end{array}$ & Ecoinvent 1.0 & $\begin{array}{l}\text { Epoxy resin, liquid, at } \\
\text { plant/RER }\end{array}$ & $\begin{array}{l}\text { Medium } \\
\text { (Eu technology) }\end{array}$ & Low & Medium-low \\
\hline $\begin{array}{l}\text { Carbon fibre (extraction } \\
\text { and production) }\end{array}$ & Idemat 2001 & Glass fibre, at plant/RER & $\begin{array}{l}\text { Medium } \\
\quad \text { (Eu technology) }\end{array}$ & Medium & Medium-low \\
\hline $\begin{array}{l}\text { Bauxite ore extracting, } \\
\text { aluminium production }\end{array}$ & $\begin{array}{l}\text { Ecoinvent } \\
1.0\end{array}$ & $\begin{array}{l}\text { Aluminium, production } \\
\text { mix, wrought alloy, at } \\
\text { plant/RER }\end{array}$ & $\begin{array}{l}\text { Medium } \\
\quad \text { (Eu technology) }\end{array}$ & Good & Medium-low \\
\hline $\begin{array}{l}\text { Bondex resin (extraction } \\
\text { and production) }\end{array}$ & Ecoinvent 1.0 & $\begin{array}{l}\text { Epoxy resin, liquid, at } \\
\text { plant/RER }\end{array}$ & $\begin{array}{l}\text { Medium } \\
\quad \text { (Eu technology) }\end{array}$ & Low & Good \\
\hline
\end{tabular}


energy required during use of the car-body, and the electricity production mix.

Apart from the route's length and topography, the energy required to operate the train depends on the train's weight and shape (aerodynamic drag factor). Since the shape is the same for all car-bodies considered here, most of the energy consumption variation will be due to weight differences. Lighter trains require less total energy, in part due to less running, shock and gradient resistance. Mainly though, the potential for faster acceleration allows a lower cruising speed for the same journey time, which lowers aerodynamic resistance. A relation was derived using the Railnet II model (Rivier and Tzieropoulos Rivier et al. 1987) developed by the LITEP (Laboratory of Intermodality, Transports and Planification of the EPFL), based on the specific train run characteristics (weight, tractive effort versus speed, brake percentage, generative brakes, resistances, gradients, stops, speed limits, etc.). This analysis showed that for this specific regional train and route, an average weight increase of one tonne for the car-body results in an average increase in energy demand of $0.0259 \mathrm{kWh} / \mathrm{km}$ (Fig. 5). The composite car-body weighs one third less than the steel car-body, and thus represents an interesting design option for reducing the use phase energy and therefore overall energy consumption. This importance of reducing energy consumption in the use phase is consistent with the study conducted by Helms and Lambrecht (2007), which shows the crucial role played by reduction in vehicle weight.

\subsection{LCI results}

Inventory results (Fig. 6) are illustrated with the following selection of key parameters: Non-Renewable Primary Energy (expressed in $\mathrm{MJ}-\mathrm{eq}$ ), and $\mathrm{CO}_{2}$ and $\mathrm{NO}_{\mathrm{x}}$ emissions.

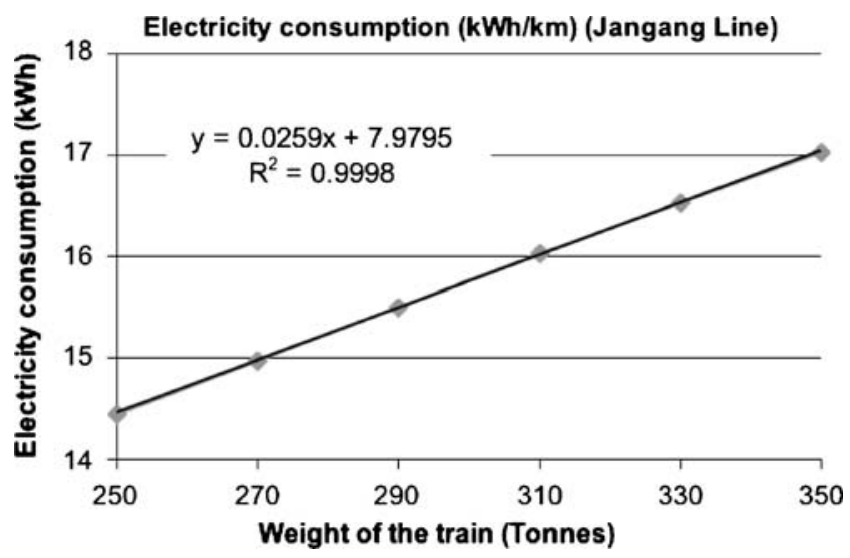

Fig. 5 Additional energy consumption per additional tonne and $\mathrm{km}$ on the Jangang line.
For all scenarios, the use phase is the most important phase (responsible for more than $80 \%$ of emissions). These inventory results show that the composite scenarios have the lowest environmental impacts; since the full composite scenario is lightest, it requires the least primary energy. With $22 \cdot 10^{6} \mathrm{MJ}$-eq, the composite hybrid scenario requires $3 \%$ and $25 \%$ less energy than the steel and aluminium scenarios, respectively. These results are largely explained by the lower energy demand during the use phase because of the reduction in weight associated with the composite car-body.

$\mathrm{CO}_{2}$ emissions assessment results show the same trend for the composite scenarios. The full composite scenario is the best alternative, followed by the hybrid composite scenario, which would be responsible for 900 tons of $\mathrm{CO}_{2}$ emitted during its whole life cycle (which correspond to about $120 \mathrm{~g} / \mathrm{km}$ ). This is respectively $5 \%$ and $26 \%$ lower than the Aluminium and Stainless steel scenarios. Similar results are observed for $\mathrm{NO}_{\mathrm{x}}$ emissions. The energy consumption and emissions during the end-of-life phase are negligible for all scenarios in the three selected inventory indicators, The recycling rate, however, can significantly affect the use of raw material.

\section{LCIA and cost assessment}

\subsection{LCIA method}

The Life Cycle Impact Assessment was performed with the Impact 2002+ analysis method (Jolliet et al. 2003). In this impact assessment model, all types of life cycle inventory results (elementary flows and other interventions) are first related to fourteen mid-point categories (Human toxicity, Respiratory effects, Ionizing radiation, Ozone depletion, Photochemical oxidant formation, Aquatic ecotoxicity, Terrestrial ecotoxicity, Aquatic eutrophication, Terrestrial eutrophication and acidification, Land occupation, Global warming, Non renewable Energy, and Mineral extraction), expressing all midpoint scores in units of a reference substance. These midpoint scores are then related to 4 damage scores in the following categories: Human health, Ecosystem Quality, Climate Change and Resource depletion. IMPACT 2002+ includes the development of new concepts and methods, especially for the comparative assessment of human toxicity and eco-toxicity. Among the new methods, Human Damage Factors are calculated for carcinogens and non-carcinogens, employing intake fractions, best estimates of dose-response slope factors, and severities. Additionally, rather than using consumption surveys, the transfer of contaminants into human food is now based on agricultural and livestock production levels. The other midpoint categories in IMPACT 2002+ are 

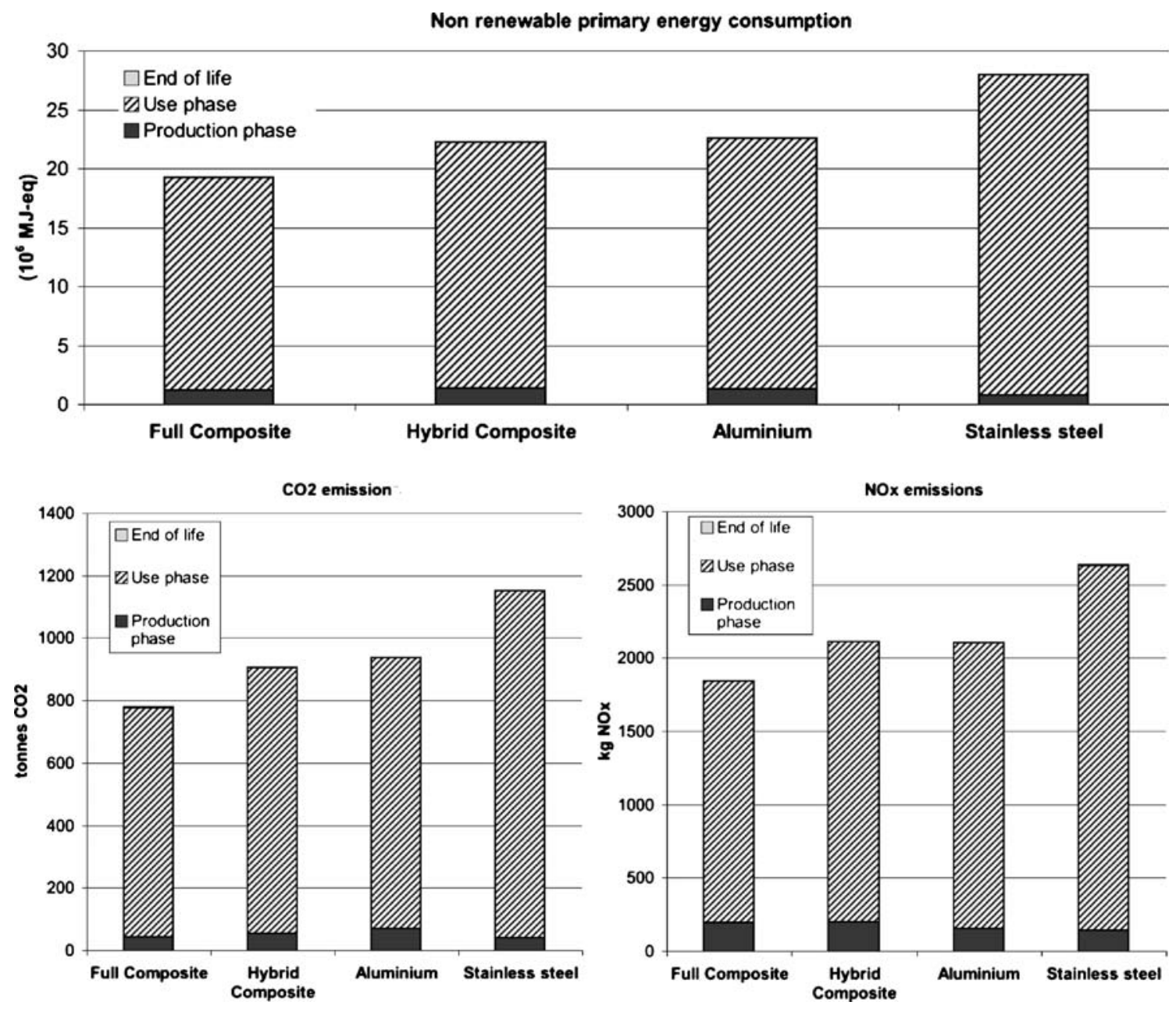

Fig. 6 LCI results : Energy, $\mathrm{CO}_{2}$ and $\mathrm{NOx}$ inventories

adapted from existing characterizing methods (Eco-indicator 99 and CML 2002). Normalization can be performed either at midpoint or at damage level, the latter being recommended in priority. The IMPACT $2002+$ method presently provides characterization factors for almost 1,500 different LCI-results, which can be downloaded at http:// www.epfl.ch/impact.

\subsection{LCIA results}

Comparative Impact 2002+ damage categories for the full life cycle are shown in Fig 7. As expected, the impact assessment shows that the use phase dominates in all categories and for all scenarios. The 'Resource depletion' damage category shows results similar to 'non-renewable energy usage'.

The comparison of the environmental impacts of the four scenarios shows that the steel scenario is in all situations the least favourable, with about $40 \%$ more emissions and impacts than the full composite scenario.
These results thus strengthen the environmental advantage of implementing composite solutions for the carbody. For all scenarios, the use phase accounts for more than $80 \%$ of the impact. However, the production phase is non-negligible and could represent $2-20 \%$. The endof-life phase is negligible in all configurations. Because of the large damage contribution by the use phase (and thus the importance of minimizing energy used in transport), the composite scenarios represent a good design option. Full composite scenarios showed the lowest impacts in all midpoint categories except for terrestrial ecotoxicity, where the hybrid composite scenario yields a lower impact.

The use phase, which dominates the car-body impacts, is itself largely influenced by the electricity production mix used. To investigate the sensitivity of the results to the electricity production mix, European and Korean production mixes were compared. The Korean electricity mix results in a higher primary energy demand (12\% higher for the hybrid composite scenario) and higher $\mathrm{CO}_{2}$ and $\mathrm{NO}_{\mathrm{x}}$ emissions. $\mathrm{SO}_{2}$ emissions 
Fig. 7 Impact $2002+$ LCIA results. 1 -Full composite, 2-Hybrid composite, 3Aluminium, 4-Steel

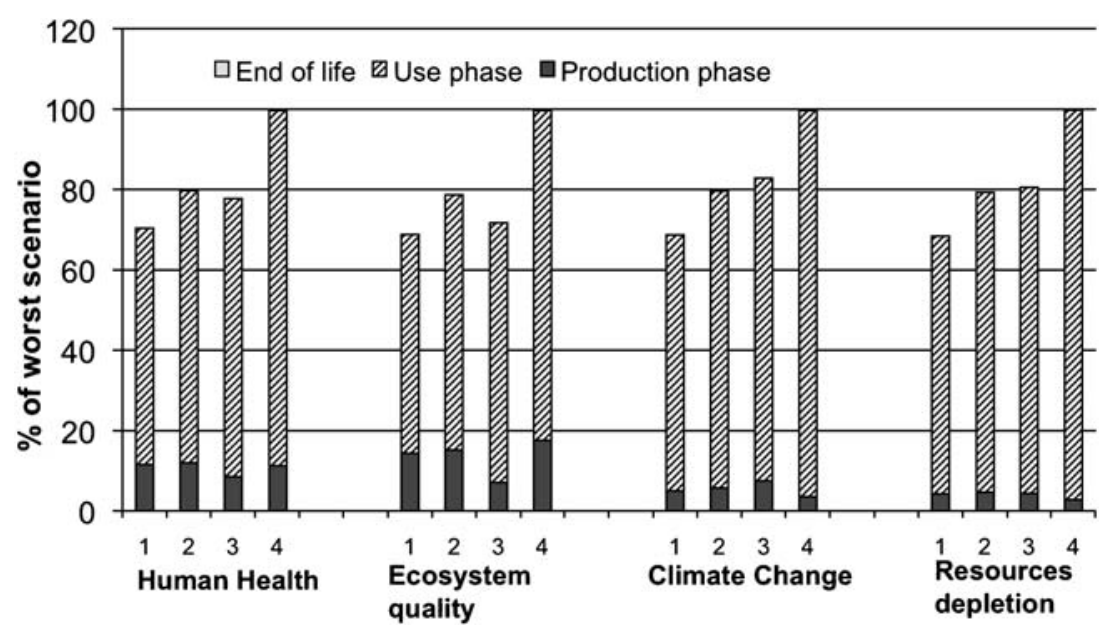

are found to be lower for the Korean production mix due to a lower fraction of lignite in the Korean electricity mix.

\subsection{Life cycle costing and technical cost modelling results}

The Technical Cost Modelling method used here (Wakeman and Månson 2005) is particularly adapted to assess composite material manufacturing costs. More detail of the rail carriage cost analysis is given by (Ecabert et al. 2006). Basically, the specific manufacturing costs were evaluated for the composite scenarios (1 and 2), with three variants on the manufacturing processes:

- Use of prepreg and autoclave curing;

- Use of prepreg and oven curing;

- Resin infusion of non-crimp carbon fibre fabrics.

The cost model evaluated the influence of machines and plant dedication to the car-body production. The fully utilised case considered that any remaining plant capacity was used and, hence, paid for by a different client or product, while the dedicated case considered that the full plant cost was amortised over the number of rail carriages produced. Other parameters that can greatly influence global costs (and which have been varied to explore sensitivity) are the number of parts that could be produced each year (production volume), and the number of worker shifts per day (between one and three). The steel and aluminium carriage costs were given by the KRRI and were hence not specifically modelled.

Manufacturing costs for the full composite scenario, produced at 90 parts per year, are segmented as follows: raw materials represent $37 \%$ of the cost (due to the cost of the CFRP prepreg material), $27.5 \%$ are linked to direct labour, $17.5 \%$ to the sub-contracted under frame, $7.5 \%$ to overheads, $5.5 \%$ to tooling, $3 \%$ to energy and $2 \%$ to equipment.

Raw materials are the main cost for the manufacturing phase and, for large production volumes, there is no significant difference between autoclave curing and oven curing, which both use pre-impregnated composite mats. Resin infusion may be a good choice for manufacturing cost reduction (Fig. 8), as dry fiber mats are used and the polymer infusion is made in-situ, which is less expensive than using prepreg. However, the structural properties of
Fig. 8 Cost/Volume curves, utilisation-based scenarios, as a percentage of most expensive case

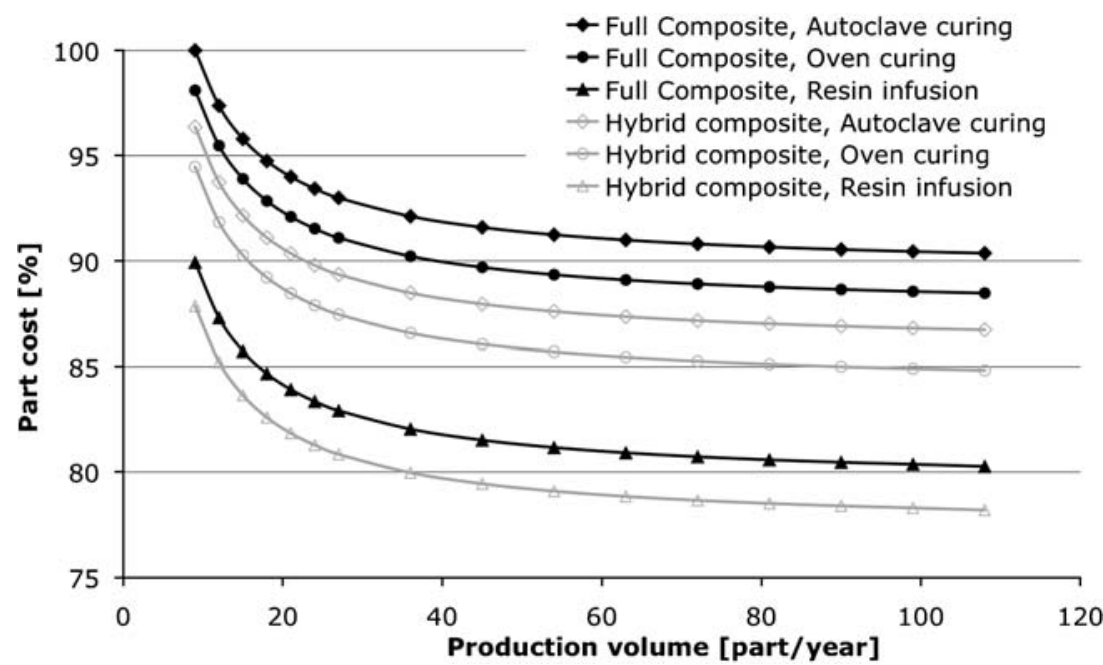


Fig. 9 Cost versus energy consumption for the analysis

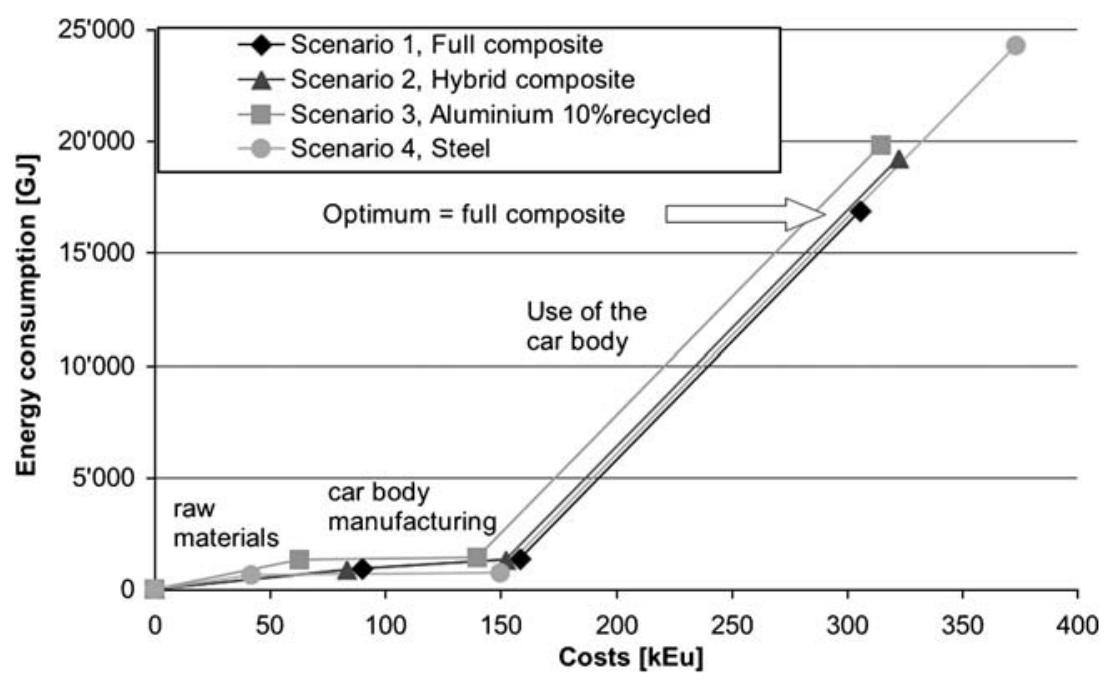

resin infused car-bodies will tend to be of lower quality than autoclave cured car-bodies and may reduce the life span of the car-bodies.

The life cycle costing results combine TCM results for the manufacturing phase (resin infusion) with operating costs. As for environmental impacts, the operating costs are considered as relative costs, where only the costs of energy attributable to mass transportation are evaluated. Aerodynamic performance and costs for operation and maintenance are considered to be the same for all scenarios. These results are presented and discussed in conjunction with LCA results in the next paragraph.

\subsection{Global discussion of the coupled LCA and TCM results}

In order to demonstrate the coupled environmental and cost analysis, non-renewable primary energy use was selected to indicate environmental impacts. The combined LCA-LCC analysis (Fig. 9) shows that the raw material and manufac- turing costs are important $(40-52 \%$ of the total life cycle costs), while the environmental impacts of these phases is quite low (3-8\%). For the raw material production phase, metallic materials are cheaper to produce but require more energy than composite materials (notably for aluminium). Steel is the lowest cost raw material, but it is also the heaviest system, which significantly increases the use-phase energy use, resulting in both the highest life cycle costs and impacts.

The use costs of the car-body are important for all scenarios relative to the whole life cycle cost $(48-60 \%)$. The steel scenario is more expensive to produce than the other scenarios, and heavier, and thus requires more energy for its operation. Compared to the steel scenario, the hybrid composite scenario is less expensive and has a reduced energy consumption over its whole life cycle. It is comparable to the aluminium scenario both in terms of costs and energy consumption. The full composite variant gives the optimum solution with the lowest life cycle costs and the smallest environmental impacts.
Fig. 10 Sensitivity study : influence of aluminium recycling on global results

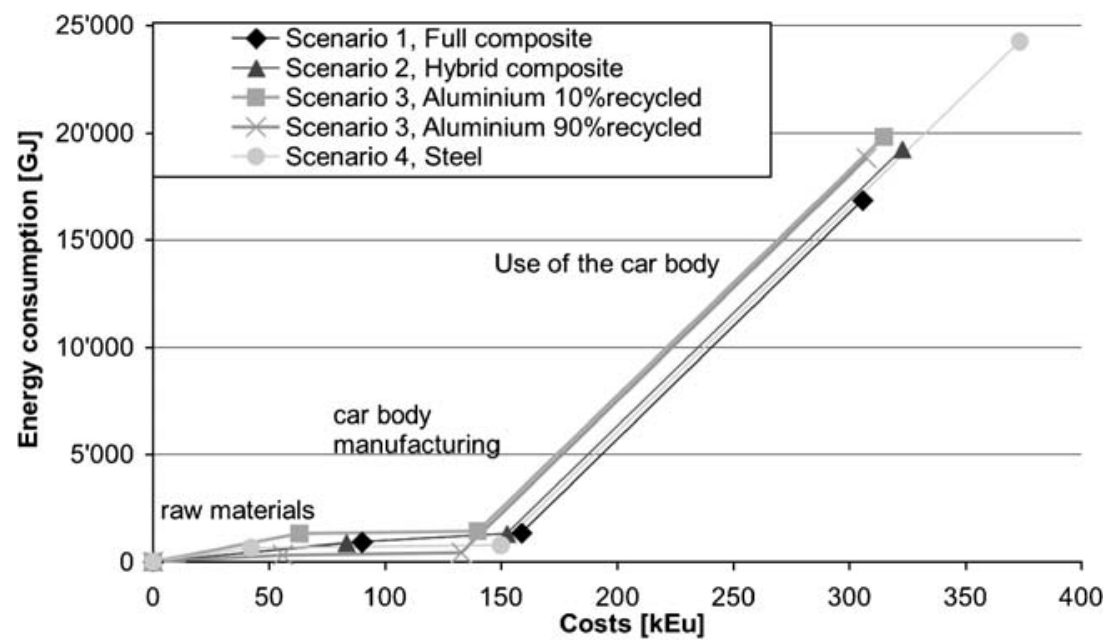


A sensitivity study has been carried out in order to evaluate the importance of recycling for the aluminium scenario. With the $90 \%$ recycling rate, this aluminium scenario has a comparable environmental performance to the hybrid composite scenario, but the full composite scenario remains best due to its superior performance during the use phase. The reduction in cost due to the use of aluminium scrap makes the cost of the aluminium scenario comparable to the full composite one (Fig. 10).

Even if manufacturing costs are relatively high, the overall costs are also dependent on the use phase costs. These use costs are found to be highly correlated to the weight of the train structure.

The costs discussed above were calculated using only European costs since Korean data were not available for all scenarios. Korean cost data were available for the two composite scenarios, we therefore have compared these data to the European hybride composite cost data in order to better understand the difference between European and Korean costs. While environmental impacts are generally similar, costs are significantly reduced in Korea. Raw material costs are similar in both regions, but manufacturing and use costs are both reduced by about $60 \%$ in Korea compared to Europe. Overall, the Korean costs amount to $56 \%$ of the European ones, with raw material costs playing a much more important role in Korea than in Europe (26\% of the total European costs versus $47 \%$ for Korea).

\section{Conclusions}

In conclusion, this study shows that a detailed and modular total cost assessment coupled with an LCA is a very relevant and efficient way to get an accurate and useful overall industrial assessment. Once detailed, cost data have been collected, and it is relatively easy to link them to an LCA database to extend the cost study to environmental performance. In this specific case study, the use phase clearly had the biggest impact on the environment over the whole life cycle for all four scenarios, with limited contributions from the other phases. The recycling of aluminium, however, is important to consider for both energy and costs. To reduce energy consumption in the use phase, the rail carriage weight is a key factor. The composite scenarios therefore represent a credible option for reducing weight and costs. The LCA showed that the full composite scenarios had the lowest impact for all but one midpoint category. Concerning the costs, the full composite car-body is the most expensive to manufacture, but the reduction in rail carriage weight enabled large energy savings in the use phase and, hence, an overall life cycle cost reduction. This coupled cost and life cycle assessment demonstrates that the full composite variant is clearly the optimum solution.

Acknowledgements This work is the result of a collaboration between Hankuk Fiber Glass Co., the Korea railroad research institute (KRRI) and Ecole Polytechnique Fédérale de Lausanne (EPFL) represented by the Laboratory of Ecosystem Management (GECOS) for the LCA study, the Composites and Polymers Technology Laboratory (LTC) for the technical cost modelling (TCM) study of candidate composite manufacturing processes, and the Laboratory for Intermodality, Transport and Planning (LITEP) for use phase energy modelling.

\section{References}

Althaus H-J, Blaser S, Classen M, Jungbluth N (2003) Life Cycle Inventories of Metals. Final report ecoinvent 2000 No. 10. EMPA Dübendorf, Swiss Centre for Life Cycle Inventories, Dübendorf.

Bage G, Samson R (2003) The Econo-Environmental Return (EER). A Link between environmental impacts and economic aspects in a life cycle thinking perspective. Int $\mathrm{J}$ Life Cycle Assess 8 (4):246-51

Bartlett N (2000) Trains in the 21st century. Design News, 4.1.2000. http://www.designnews.com/article/CA137910.html

Batchelor J (1981) Use of fibre reinforced composites in modern railway vehicles. Materials in Engineering 2(4):172-182

Baumgartner T, Tietje O, Spielmann M, Bandel R (2000) Ökobilanz der Swissmetro, Umweltwirkungen durch Bau und Betrieb (Teil 1) und durch induzierte Aktivitäten (Teil 2). Berne

Campbell FC (2004) Manufacturing processes for advanced composites. Elsevier, Oxford

Carruthers J (2004) The research requirements of the transport sectors to facilitate an increased usage of composite materials, Part III: The composite material research requirements of the rail industry. June 2004, ComposiTN

Dahlbo H, Ollikainen M, Peltola S, Myllymaa T, Melanen M (2007) Combining ecological and economic assessment of options for newspaper waste management. Resources, Conservation and Recycling 51:42-63

Dones R, Bauer C, Bolliger R, Burger B, Faist Emmenegger M, Frischknecht R, Heck T, Jungbluth N, Röder A (2004) Life Cycle Inventories of Energy Systems: Results for Current Systems in Switzerland and other UCTE Countries. ecoinvent report No. 5. Paul Scherrer Institut Villigen, Swiss Centre for Life Cycle Inventories, Dübendorf.

EAA (2009) European Aluminium Association website. Recycled aluminium. http://www.eaa.net/en/about-aluminium/productionprocess/recycled-aluminium/ Accession date 25.02.2009

Ecabert B, Wakeman MD, Blanc I, Jolliet $\mathrm{O}$, Lee S, Månson JAE (2006) Coupled cost and life cycle modelling of composite car-bodies for the Korean tilting train. Proceedings of the 27th SAMPE International Conference Europe, March 2006, Paris

Frischknecht R, Jungbluth N, Althaus H-J, Doka G, Dones R, Heck T, Hellweg S, Hischier R, Nemecek T, Rebitzer G, Spielmann M (2005) The ecoinvent database: Overview and methodological framework. Int J Life Cycle Assess 10(1):3-9

Gibson TL (2000) LCA of Advanced Materials for Automotive Applications, Proceedings of The 'Total Life Cycle Conference, Land. Sea \& Air Mobility', SAE International

Guillemot JM, Grunevald YH (2000) Les composites en construction ferroviaire, Techniques de 1'Ingénieur, traité Plastiques et Composites, AM 5650 
Guinèe JB, Gorrée M, Heijungs R, Huppes G, Kleijn R, de Koning A, van Oers L, Wegener Sleeswijk A, Suh S, Udo de Haes HA, de Bruijn H, van Duin R, Huijbregts MAJ, Lindeijer E, Roorda AAH, Weidema BP (2001) Life cycle assessment - An operational guide to the ISO standards; Characterisation and Normalisation Factors. Retrieved 17.02.2004

Helms H, Lambrecht U (2007) The Potential Contribution of LightWeighting to Reduce Transport Energy Consumption. Int J Life Cycle Assess 12(1):58-64 Special issue

Hunkeler D, Lichtenvort K, Rebitzer G (2008) Environmental life cycle costing. CRC Press. ISBN: 978-1-4200-5470-5

IDEMAT (2001) IDEMAT database. Delft University of Technology, Delft, The Netherlands

IEC60300 (1996) International Electrotechnical Commission standard, 1996, NO. 60300

ISO 14040 (2006) International Standard. Environmental management Life cycle assessment - Principles and framework, International Organization for Standardization, Geneva.

ISO 14044 (2006) International Standard. Environmental management Life cycle assessment - Requirements and Guidelines, International Organisation for Standardisation, Geneva.

Jolliet O, Saadé M, Cretaz P (2005) Analyse de cycle de vie comprendre et réaliser un écobilan. Presses Polytechniques et Universitaires Romandes, Lausanne

Jolliet O, Margni M, Humbert S, Rebitzer G, Rosenbaum R (2003) Impact 2002+: a new life cycle impact assessment methodology. Int J Life Cycle Assess 8(6):324-330

KELA (2005) Korean Database (extraction) for electricity production

Kirimura K, Tsujimura T, Mifune N (1997) Railway materials tending to be increasingly environment-conscious in Japan. Proceedings of the World Congress on Railway Research, Italy

Maibach K, Peter D, Seiler B (1999) Ökoinventar Transporte, Grundlagen für den ökologischen Vergleich von Transportsystemen und den Einbezug von Transportsystemen in Ökobilanzen, 2. korrigierte Auflage. Swiss National Science Foundation, Zü

Margand A, Payet J, Jolliet O (2003) Life cycle assessment of an underbody panel for car. In preparation for publication, Swiss Federal Institute of Technology of Lausanne $16 \mathrm{pp}$

Mingot S, Baumgartner T (1997) Ökobilanz Swissmetro. LCA für ökologische Optimierung \& Vergleich mit anderen Verkehrsmitteln, Zürich
Nagatomo T, Miyauchi T, Tsuchiya H (1997) Preliminary investigation for life cycle assessment (LCA) of Shinkansen vehicles. Proceedings of the World Congress on Railway Research, Italy

Nolte R (2003) EVENT Evaluation of Energy Efficiency Technologies for Rolling Stock and Train Operation of Railways. Final report. International Union of Railways. Deutsche Bahn AG, Berlin

Norris G (2001) Integrating life cycle cost analysis and LCA. Int J Life Cycle Assess 6(2):118-20

Rivier RE, Tzieropoulos P, EPFL-LITEP (1987) Computer-aided planning for railway network, lines and stations. In: Computers in Railway Management, Computational Mechanics Publications. Springer-Verlag, Berlin, pp 3-16

Rebitzer G, Hunkeler D, Jolliet O (2003) LCC- The economic pillar of sustainability: methodology and application to wastewater treatment. Environmental Progress 22(4):241-249

Robinson M (2000) Applications in Train and Railways. In: Comprehensive Composite Materials. Vol. 6, Elsevier Science Ltd

Spielmann M, Kägi T, Stadler P, Tiethe O (2003) Life Cycle Inventories of Transport Services, 2003, in Ecoinvent database 1.01, Ecoinvent reports No 14, Swiss Centre for Life Cycle Inventories, Dübendorf

Spielmann M, Scholz RW (2005) Life cycle inventories of transport services: Background data for freight transport. Int J Life Cycle Assess 10(1):85-94

The Global Aluminium Recycling Committee (2006) Global Aluminium Recycling: A Cornerstone of Sustainable Development, International Aluminium Institute, London. http://www.worldaluminium.org/cache/f10000181.pdf

Von Rozycki C et al (2003) Ecology profile of the German high-speed rail passenger transport system, ICE. Int J Life Cycle Assess 8 (2):83-91

Vogtländer J, Brezet H, Hendricks C (2001) The virtual Eco-Costs '99. Int J Life Cycle Assess 6(2):157-66

Wakeman, MD, Månson, JAE (2005) Design and Manufacture of Textile Composites Chapter 11: Cost analysis, Ed. A. Long, Woodhead, published spring 2005, Clark JP, Roth R, Eds. 'Techno-Economic issues in materials selection', Materials selection and design, Materials Park, OH, ASM International

Wilson M for 'Bombardier Transportation' (2002) Composite Materials For Railway Applications, Genoa, June 2002 